\title{
76. The Spontaneous-Diabetes Rat: A Model of Noninsulin Dependent Diabetes Mellitus*)
}

\author{
By Yoshio Goto and Masaei KaKIZAKI \\ The Third Department of Internal Medicine, Tohoku University \\ School of Medicine, Sendai \\ (Communicated by Toshio Kurokawa, M. J. A., Dec. 12, 1981)
}

Introduction. In spite of a brilliant advance of medical science, there are enormous number of diseases of constitutional or endogenous nature, of which etiologies are still unknown or unclear and are called or classified as essential or idiopathic. Diabetes mellitus is a disease of this category.

We have continued an experiment to produce diabetic rats from normal rats by repetition of selective breeding under the following working hypothesis: If, from a normal population, animals with a slightly impaired glucose tolerance are selected and mated, their offspring may show a greater impairment of glucose tolerance than the parents. If this is so, the repetition of this procedure over several generations would finally produce diabetic animals. Our experiment using rats of Wistar strain started from 1973 and could demonstrated a propriety of the hypothesis.

Methods and results. A stock of 211 Wistar rats (130 males and 81 females) supplied by the Nogawa Farm of Japan Clea Co., were used. They were fed commercial animal food ad libitum. Oral glucose tolerance test (GTT) was performed in these rats when they weighed $150-200 \mathrm{~g}$ and the rats with a slight glucose intolerance were selected for the breeding. GTT was performed after $12 \mathrm{hr}$ fasting. Glucose solution ( $2 \mathrm{~g}$ per $\mathrm{kg}$ of body weight) was administered orally by a catheter attached to a syringe and $0.05 \mathrm{ml}$ of blood was collected every $30 \mathrm{~min}$ for two hours by tail bleeding. Blood glucose was estimated by the glucose-oxidase method. The degree of glucose intolerance was expressed as the sum of blood glucose values at five timepoints, i.e., fasting, $30,60,90$, and $120 \mathrm{~min}$. The details of the experimental procedure were described elsewhere. ${ }^{1)}$ Of the 211 stock rats, 18 rats were selected for the breeding and 162 offspring $\left(F_{1}\right)$ were obtained. GTT was carried out in these $F_{1}$ rats, 25 rats were selected and mated, and $204 \mathrm{~F}_{2}$ rats were obtained. This procedure was repeated in each generation. The selective breeding only was

*) This work was supported by scientific research grant from the Ministry of Education of Japan (no. 348170). 
Table I. Mean glucose tolerance tests

\begin{tabular}{cc|rcccc}
\hline \multirow{2}{*}{$\begin{array}{c}\text { Genera- } \\
\text { tion }\end{array}$} & $\begin{array}{c}\text { Num- } \\
\text { ber }\end{array}$ & \multicolumn{5}{|c}{ Blood glucose (mg.per $100 \mathrm{ml})}$. \\
\cline { 3 - 7 } & & Fast & $30 \mathrm{~min}$ & $60 \mathrm{~min}$ & $90 \mathrm{~min}$ & $120 \mathrm{~min}$ \\
\hline $\mathrm{P}$ & 211 & $79.9 \pm 11.9$ & $140.5 \pm 18.6$ & $130.9 \pm 18.4$ & $109.4 \pm 16.3$ & $98.5 \pm 13.5$ \\
$\mathrm{~F}_{1}$ & 162 & $95.2 \pm 11.6$ & $162.9 \pm 24.9$ & $143.5 \pm 21.1$ & $124.2 \pm 14.1$ & $113.8 \pm 12.7$ \\
$\mathrm{~F}_{2}$ & 202 & $102.9 \pm 16.4$ & $187.4 \pm 31.9$ & $158.4 \pm 30.6$ & $137.4 \pm 25.0$ & $125.0 \pm 22.4$ \\
$\mathrm{~F}_{3}$ & 175 & $102.9 \pm 12.6$ & $197.2 \pm 38.1$ & $180.1 \pm 38.5$ & $153.6 \pm 35.7$ & $138.4 \pm 32.1$ \\
$\mathrm{~F}_{4}$ & 215 & $102.4 \pm 16.4$ & $202.3 \pm 31.6$ & $175.9 \pm 32.2$ & $147.7 \pm 24.9$ & $132.9 \pm 21.1$ \\
$\mathrm{~F}_{5}$ & 207 & $101.8 \pm 15.9$ & $186.3 \pm 26.7$ & $176.1 \pm 27.7$ & $148.6 \pm 25.0$ & $128.7 \pm 19.8$ \\
$\mathrm{~F}_{6}$ & 103 & $100.9 \pm 18.4$ & $228.0 \pm 39.9$ & $228.5 \pm 46.2$ & $192.5 \pm 46.3$ & $162.4 \pm 40.4$ \\
$\mathrm{~F}_{7}$ & 122 & $107.2 \pm 16.8$ & $247.1 \pm 36.3$ & $250.4 \pm 45.2$ & $214.9 \pm 47.5$ & $183.2 \pm 44.1$ \\
$\mathrm{~F}_{8}$ & 78 & $100.6 \pm 12.7$ & $261.7 \pm 30.2$ & $278.2 \pm 28.7$ & $240.0 \pm 30.3$ & $195.9 \pm 27.4$ \\
$\mathrm{~F}_{9}$ & 68 & $107.5 \pm 13.9$ & $275.9 \pm 26.7$ & $292.5 \pm 27.7$ & $255.2 \pm 30.5$ & $211.3 \pm 29.1$ \\
$\mathrm{~F}_{10}$ & 68 & $113.8 \pm 11.0$ & $265.7 \pm 29.3$ & $304.4 \pm 27.9$ & $277.7 \pm 30.7$ & $240.6 \pm 31.9$ \\
$\mathrm{~F}_{11}$ & 82 & $123.4 \pm 15.3$ & $265.4 \pm 34.9$ & $291.3 \pm 27.5$ & $266.1 \pm 32.8$ & $231.7 \pm 36.2$ \\
$\mathrm{~F}_{12}$ & 21 & $122.4 \pm 27.7$ & $259.4 \pm 30.9$ & $313.0 \pm 42.6$ & $303.2 \pm 46.0$ & $265.7 \pm 40.3$ \\
$\mathrm{~F}_{13}$ & 56 & $123.3 \pm 19.3$ & $267.3 \pm 27.2$ & $319.9 \pm 34.7$ & $300.9 \pm 34.0$ & $261.5 \pm 33.8$ \\
$\mathrm{~F}_{14}$ & 60 & $111.7 \pm 17.9$ & $261.0 \pm 24.4$ & $322.0 \pm 28.9$ & $312.6 \pm 31.2$ & $277.1 \pm 34.3$ \\
$\mathrm{~F}_{15}$ & 45 & $110.3 \pm 14.0$ & $274.6 \pm 33.7$ & $329.8 \pm 32.1$ & $323.1 \pm 28.7$ & $287.2 \pm 28.2$ \\
\hline
\end{tabular}

Mean士S. D.

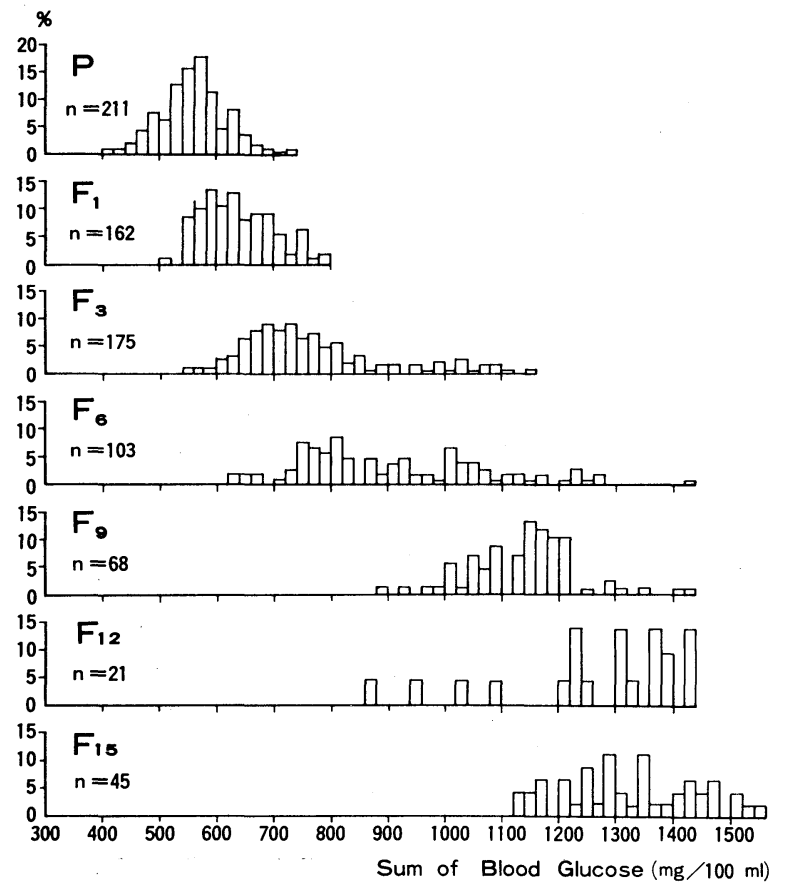

Fig. 1. Change of the distribution of the sum of blood glucose. 
continued until the mating of $\mathrm{F}_{3}$ rats and brother-sister mating was avoided. However, as sib-breeding is a quicker way for intensifying the abnormal tendency, sib-breeding was carried out from $\mathrm{F}_{4}$ rats in addition to the selective breeding.

The mean glucose tolerance tests of each generation are shown in Table $I$ and change of the distribution of the sum of blood glucose is depicted in Fig. 1. Glucose intolerance became obvious with an advance of the generation and an increase in the peak and the two hour values was more remarkable in comparison with that of the fasting values, although some of the rats after the 7 th generation had a fasting level exceeding $150 \mathrm{mg} / 100 \mathrm{ml}$. The distribution curve of the sum of blood glucose of the stock rats obtained from the experimental animal farm was regular (Gaussian curve) and the values distributed within a relatively narrow range as seen in the upper part of the figure. The distribution curves shift to the right with an advance of the generation and all of the sum values deviate from the normal range from the $F_{9}$ generation. The glucose intolerance was demonstrated from two weeks after birth in $F_{13}$ rats.

The mean body weight of the spontaneous-diabetes rats was not greater, but slightly less than that of the age and sex-matched normal Wistar rats, although the difference was not significant. Thus the diabetic state is not associated with obesity in these rats. There was no sex difference in occurrence or severity of the diabetic state.

Oral glucose administration provoked a sluggish plasma insulin response in comparison with that of normal Wistar rat. Perfusion experiments of the isolated pancreas of the diabetic rats showed that an abrupt increase in glucose concentration of the perfusate produced a typical diabetic insulin secretion pattern, i.e., a lack of the first rapid phase and a low second phase response.2) Thickening of the glomerular capillary basement membrane and slowing of the conduction velocity

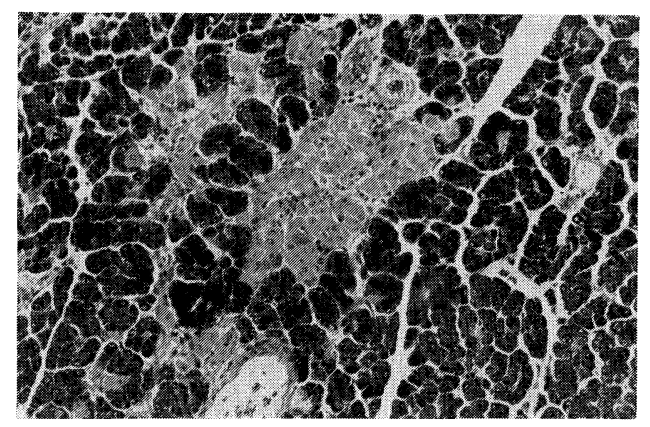

Fig. 2. The islet of the pancreas of 18 months old $\mathrm{F}_{13}$ male rat. 
of impulse in the tail motor nerve were also confirmed. ${ }^{3), 4)}$ Histological studies revealed that the islets of the pancreas losed their round shape and showed an irregular star-fish like shape from four months after birth as shown in Fig. 2. However, no cell infiltration was observed.

Comment. The present experiment demonstrated clearly that spontaneous-diabetes rats can be produced from normal rats by repetition of the selective breeding and this result seems to support the polygenic theory ${ }^{5), 6}$ rather than the theory assuming a special diabetes gene. ${ }^{\text {) }}$ Furthermore, the result suggests a possibility to produce malady-model animals of other endogenous disorders by similar procedures, if any sensitive indicators are present for the selection. It may be noteworthy that the chronic complications such as neuropathy and microangiopathy characteristic of diabetes mellitus did occur in these rats despite the selection was carried out by using only blood glucose as an indicator.

Summary. We succeeded to produce spontaneous-diabetes rats from normal Wistar rats by repetition of the selective breeding. Oral glucose tolerance test was used for the selection as an indicator. The result indicates that the inheritance of diabetes mellitus is not determined by specific gene(s) but is influenced by many genes relating to carbohydrate metabolism.

\section{References}

1) Goto, Y., Kakizaki, M., and Masaki, N.: Proc. Japan Acad., 51, 80 (1975).

2) Goto, Y., Kakizaki, M., Toyota, T., Masaki, N., Kitahara, A., Yagihashi, S., and Kimura, K.: Diabetes (ed. Bajaj, J. S.). Excerpta Medica, Amsterdam, pp. 703-710 (1977).

3) Yagihashi, S., Goto, Y., Kakizaki, M., and Kaseda, N.: Diabetologia, 15, 309 (1978).

4) Yamada, K., and Yagihashi, S.: J. Japan Diab. Soc., 23, 1012 (1980).

5) Shimpson, N. E.: Diabetes, 13, 462 (1964).

6) Mimura, G., Miyao, S., Koganemaru, K., Haraguchi, Y., Jinnouchi, T., and Hashiguchi, J.: Diabetes Mellitus in Asia, 1970 (eds. Tsuji, S., and Wada, M.). Excerpta Medica, Amsterdam, pp. 83-97 (1971).

7) Pincus, G., and White, P.: Amer. J. med. Sci., 186, 159 (1934). 